causing congenital toxoplasmosis, than during infancy. The classic triad of congenital toxoplasmosis, made up of hydrocephalus, choroiditis, and intracranial calcification, is rare; but the results of prospective studies suggest that many more infants, apparently unaffected at birth, later develop isolated clinical features such as choroiditis or neurological problems.

The incidence of congenital toxoplasmosis is difficult to state precisely because of this variable presentation and also because the level of human infection varies between urban and rural settings and across countries. In Britain about two or three women in every 1000 become infected during pregnancy, as judged by seroconversion. Nevertheless, we do not know accurately in how many of these pregnancies the babies become infected or how many of these children are clinically affected. In a London population of 3187 women studied by Ruoss and Bourne $^{2}$ seven women developed toxoplasmosis-but only one infant had a positive dye test, and none developed clinical congenital toxoplasmosis. In a Scottish study of 5576 pregnancies at risk Williams and her colleagues ${ }^{3}$ found two children with clinical toxoplasmosis (and a third with positive serological findings) from 15 women who had been infected during pregnancy. In the United States Kimball $e t a l^{5}$ found two infected children in 2765 pregnancies, neither with clinical toxoplasmosis; and Alford et al ${ }^{6}$ screened 7500 children at birth, finding 10 with evidence of infection but only one with clinical toxoplasmosis.

Other information about congenital toxoplasmosis has come from referral centres where mothers or infants are investigated because a clinician has suspected the infection. A large series in Paris ${ }^{7}$ has been analysed according to the trimester of the mother's infection. The data suggest that clinical signs are more common with infection early in pregnancy and that about $30 \%$ of infections of the mother are transmitted to the child. But because the series combined screened with referred women and the infection rate was much higher than in British studies these data are a poor indication of the incidence in Britain.

Hall's review ( $p$ 453) of the Public Health Laboratory Service reports received by the Communicable Disease Surveillance Centre has the advantage of being national (for England, Wales, and Northern Ireland) but the disadvantage of collating information from laboratories rather than clinical care. The incidence might have been underestimated in either of two ways: by clinicians not recognising the possibility of infection in symptomatic children or by the laboratories not reporting low titre, but true, infections to the Communicable Disease Surveillance Centre. This recent laboratory identification rate was much lower than in a survey 10 years ago which used similar methods. At face value, this difference would suggest a fall in incidence; but it may simply reflect a change in clinical awareness. Either way, the current levels of reporting are much lower than the estimates of incidence from prospective studies.

What are the opportunities for prevention of congenital toxoplasmosis? There is no effective live vaccine. Fewer than one third of women of reproductive age in Britain are seropositive, and reducing the rate of infection in pregnant women will prove difficult unless society changes its attitudes towards cats. The alternative is secondary prevention by serological screening and early diagnosis of infection during pregnancy. ${ }^{8}$ This might be costly, and there has been no controlled trial to show whether treatment (with spiramycin) is effective; such a trial would need surveillance of many thousands of pregnant women to gain a reliable result.

Congenital toxoplasmosis is a rare cause of mental handicap -being recorded in only one in 500 of all affected peoplewhereas Down's syndrome and birth injury together account for over half of all cases. ${ }^{9}$ We could assess the potential value of screening better if we knew more about the clinical course of toxoplasma infection in pregnancy. Paediatricians can help by keeping a high level of alertness and giving as full a clinical description as possible when seeking serological confirmation. The Public Health Laboratory Service needs to standardise the test dilutions at which the diagnosis is regarded as positive. And clinicians can help confirm-or reject-the diagnosis by remembering to submit follow up sera for testing.

MARK MCCARTHY

Senior Lecturer in Community Medicine,

University College London,

London WC1E 6JJ

${ }^{1}$ Fleck DG, Kwantes W. The laboratory diagnosis of toxoplasmosis. London: HMSO, 1980. (Public Health Laboratory Service monograph series, No 13.)

2 Ruoss CF, Bourne GL. Toxoplasmosis in pregnancy. Fournal of Obstetrics and Gynaecology of the British Commonwealth 1972;79:1115-8.

${ }^{3}$ Williams KAB, Scott JM, MacFarlane DE, Williamson JMW, EliasJones TF, Williams $\mathrm{H}$. Congenital toxoplasmosis: a prospective survey in the west of Scotland. Fournal of Infection 1981;3:219-29.

4 Broadbent EJ, Ross R, Hurley R. Screening for toxoplasmosis in pregnancy. f Clin Pathol 1981 ;34:659-64.

${ }^{5}$ Kimball AC, Kean BH, Fuchs F. Congenital toxoplasmosis: a prospective study of 4048 patients. Am $\mathcal{F}$ Obstet Gynecol 1971;111:211-8.

${ }^{6}$ Alford CA, Stagno S, Reynolds DW. Congenital toxoplasmosis: clinical, laboratory and therapeutic considerations, with special reference to subclinical disease. Bull NY Acad Med 1974;50:160-81.

${ }^{2}$ Desmonts DG, Couvreur J. Congenital toxoplasmosis: a prospective study of 378 pregnancies. $N$ Engl F Med 1974;290:1110-6.

${ }^{8}$ Wilson $\mathrm{CB}$, Remington JS. What can be done to prevent congenital toxoplasmosis ? Am $\mathcal{F}$ Obstet Gynecol 1980;138:357-63.

${ }^{9}$ Kushlick A, Cox GR. The epidemiology of mental handicap. Dev Med Child Neurol 1973;15:748-59.

\section{Myocardial infarction and the normal coronary arteriogram}

Myocardial ischaemia occurs when there is an unfavourable balance between coronary blood flow and the metabolic requirements of the myocardium. If the obstruction to flow is sufficiently prolonged it will lead to myocardial infarction. Almost all patients with a myocardial infarct have severe obstructive coronary arterial lesions, and coronary arteriography in the early hours of infarction often shows superadded thrombus that may completely occlude the vessel. Among the few exceptions are the patients with a myocardial infarction occasionally seen in whom the coronary arteriogram fails to show evidence of coronary obstructive lesions. Although pathological data would suggest that some of these so called normal coronary arteries do indeed have diffuse atheromatous narrowing, ${ }^{1}$ there is no doubt that myocardial infarction can occur in the absence of gross narrowing of the arteries.

Such myocardial infarction with angiographically normal or near normal coronary arteries is rare. The prevalence varies from $1 \%$ to $12 \%$ of patients according to the mode of investigation and the population studied. ${ }^{2}{ }^{3}$ Recent prospective studies show that in patients surviving an acute myocardial infarction normal coronary arteries are found in about 1-3\% of cases. $^{45}$ 
Classically these patients are younger than average and are often under $35,{ }^{6} 7$ with a higher proportion than usual of women. Most studies suggest that the patients do not have the classic risk factors, though McKenna and his colleagues emphasised the importance of smoking. ${ }^{8}$ The group seems, however, to be heterogeneous in its clinical presentation, and a unifying pathophysiological mechanism seems unlikely.

Several reports emphasise the sudden development of prolonged cardiac pain without any previous history of similar chest discomfort. ${ }^{56}$ After the acute event these patients usually do not develop further chest pain, and the prognosis is excellent. Prolonged treatment is rarely required. Betriu and his coworkers performed ergonovine testing in all eight of their patients with myocardial infarction and normal coronary arteries and this clinical profile; in all there was diffuse narrowing throughout the entire length of the coronary tree with no focal spasm. ${ }^{5}$ Pathological studies almost invariably show the presence of thrombus in such patients, ${ }^{3}$ and coronary angiograms performed acutely during myocardial infarction also show the importance of thrombus in the early stages of myocardial infarction. One attractive theory is that lysis or recanalisation of a thrombus may occur between the time of infarction and when the coronary angiogram is performed, usually after one to three months in most series. ${ }^{3}$ Thromboembolism or thrombosis in situ initiated by trivial irregularities in the vessel wall not visible on the angiogram are both plausible explanations of such an event. Certainly the history of a sudden single event without response to provocative testing would fit well with such a theory.

Other patients may present differently. In a recent report from Legrand and his colleagues on 1727 patients admitted to a coronary care unit over two and a half years with an acute myocardial infarction 18 patients were identified as having "normal" coronary arteries. ${ }^{7}$ Angiography was performed for one or more of the following reasons: residual myocardial ischaemia shown by typical angina pectoris or stress testing (280 patients), age under 35 (18 patients), subendocardial infarction (86 patients), malignant arrhythmias in the posthospital phase (five patients). Fifteen of the 18 patients gave a history of chest pain occurring before the acute event; the pain was often atypical, starting mainly at rest or after exercise. In these patients the clinical course was not benign in all instances: 11 patients developed chest pain at rest early after infarction. One patient treated with beta blocking drugs suffered a recurrent myocardial infarct, eight became asymptomatic, and two improved with calcium antagonists and nitrates. One patient developed a severe form of variant angina three months after the infarction, and two patients experienced rare episodes of angina at rest. The stress electrocardiogram was negative in all cases. Seven patients had a provocative test using ergonovine in the coronary care unit; two had a positive response with ST segment depression and chest pain. A further two tests were performed during cardiac catheterisation; one showed focal narrowing with angina and a raised ST segment, the other showed severe diffuse narrowing associated with chest pain but without ST segment changes.

Maseri et al had earlier suggested on the basis of their own direct observations that in such patients coronary vasospasm may (in some as yet unidentified circumstances) be responsible for myocardial infarction and thrombosis even in the absence of coronary atherosclerosis. ${ }^{9}$ Similarly as early as 1972 Cheng and his coworkers described a single case in which spasm of the circumflex coronary artery resulted in myocardial infarction. ${ }^{10}$ In this group of patients the clinical course seems to be benign provided that residual chest pain is controlled by drugs known to help coronary vasospasm (that is, calcium antagonists and nitrates).

How, therefore, should such patients be managed ? Probably all patients under the age of 40 who suffer an acute myocardial infarction should be investigated. Those with a normal coronary arteriogram can be reassured that their prognosis is good, but careful follow up is warranted and chest pain developing subsequently must be treated promptly.

\section{KIM M Fox}

Consultant Cardiologist,

National Heart Hospital,

London W1M 8BA

1 James TN. Angina without coronary disease (sic). Circulation 1970;42: $189-91$.

${ }^{2}$ Khan AH, Haywood LJ. Myocardial infarction in nine patients with radiologically patent coronary arteries. $N$ Engl f Med 1974;291:427-31.

${ }^{3}$ Arnett EN, Roberts WC. Acute myocardial infarction and angiographically normal coronary arteries: an unproven combination. Circulation $1976 ; 53: 395-40$.

${ }^{4}$ Bertrand ME, Lefebvre $M$, Laisne CL, Rousseau MF, Carre AG, Lekieffre JP. Coronary arteriography in acute transmural myocardial infarction. Am Heart $\mathcal{f}$ 1979;97:61-9.

${ }^{5}$ Betriu A, Pare JC, Sanz GA, et al. Myocardial infarction with normal coronary arteries: a prospective clinical-angiographic study. Amf Cardiol $1981 ; 48: 28-32$.

${ }^{6}$ Rosenblatt A, Selzer A. The nature and clinical features of myocardial infarction with normal coronary arteriogram. Circulation 1977;55: $578-80$.

' Legrand V, Deliege M, Henrard L, Boland J, Kutlbertus H. Patients with myocardial infarction and normal coronary arteriogram. Chest 1982; 82:678-85.

${ }^{8}$ McKenna WJ, Chew CYC, Oakley CM. Myocardial infarction with normal coronary arteriogram. Possible mechanism of smoking risk in coronary artery disease. Br Heart $\mathcal{F} 1980 ; 43: 493-8$.

${ }^{9}$ Maseri A, L'Abbate A, Baroldi G, et al. Coronary vasospasm as a possible cause of myocardial infarction. N Engl f Med 1978;299:1271-7.

${ }^{10}$ Cheng TO, Bashour J, Singh BK, Kelser GA. Myocardial infarction in the absence of coronary arteriosclerosis. Result of coronary spasm (?). Am f Cardiol 1972;30:680-2.

\section{Thoracic outlet syndrome}

The thoracic outlet compression syndrome, a term introduced by Peet $e t$ al in $1956,{ }^{1}$ refers to conditions in which nerves or vessels or both are compressed in the root of the neck or axilla. Although accepted by common usage the name is not really apt, since the structures affected pass from the neck to the arm, the only thoracic contribution being provided in some instances by the first rib functioning as the lower blade of a pincer whose upper blade is the clavicle.

The syndrome includes a perplexing group of disorders such as cervical rib, scalenus anterior syndrome, costoclavicular compression, abnormalities of the clavicle, and venous or arterial compressions. Patients with these conditions are difficult to assess, so they are apt to be referred to many different specialists including psychiatrists. Parry has made a convincing case for combined assessment by orthopaedic surgeon, neurologist, and vascular surgeon. ${ }^{2}$

The neurological varieties of the syndrome, which constitute $80-90 \%$ of most series, are more common in women, typically of slim build and drooping shoulders. Vascular compression is more often seen in men.

Patients presenting with vascular symptoms should be investigated without delay. Lesions in the subclavian artery such as stenosis or aneurysm can give rise to microemboli, which may lead to irreversible damage to the hand, or may thrombose completely endangering the entire limb. 